\title{
Could antivirals be used to treat Alzheimer's disease?
}
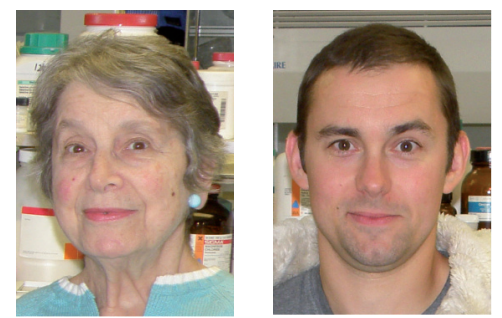

"... antiviral treatment of the disease might slow or stop its progression in those patients who are seropositive for HSV1 ... and who are APOE- $\varepsilon 4$ carriers."

\section{Ruth F Itzhaki* \& Matthew A Wozniak}

Faculty of Life Sciences, The University of Manchester, Stopford Building, Oxford Road, Manchester M13 9PT, UK

*Author for correspondence: Tel.: +44 1613063879 m. ruth.itzhaki@manchester.ac.uk

Alzheimer's disease (AD) is a devastating disease that robs victims of their memory, cognition and personality, and causes great stress and suffering not only to patients but also to those who care for them. There is currently no effective treatment nor any proven way of prevention, despite the enormous sums that have been poured into research and clinical trials, yet the need is overwhelming. Some 18 million people worldwide suffer from the disease and the numbers are predicted to increase several fold in the next few decades. The cost in economic terms is huge; in 2010 it was estimated to be US $\$ 604$ billion worldwide, and will increase in parallel with the increased numbers, unless a treatment strategy is soon found. One strategy might be to use antiviral agents to combat the disease. This possibility is based on data suggesting that herpes simplex virus type 1 (HSV1), the virus responsible for herpes labialis (cold sores), is a cause of AD.

The reasons that HSV1 was suggested to play a role in $\mathrm{AD}$ relate to several features of $\mathrm{AD}$ epidemiology and pathology (reviewed in [1]), including the fact that the main symptoms of $\mathrm{AD}$ - memory loss and cognitive impairment occur in survivors of herpes simplex encephalitis (HSE), a rare and very serious brain disorder caused by HSV1, and that the brain regions afflicted in HSE - the frontal and temporal cortices - are primarily affected in AD. Subsequently, it was demonstrated that a high proportion of brains of elderly people, including brains from AD sufferers, contain latent HSV1 DNA specifically in these regions and that the virus is active in human brain [1]. The presence of HSV1 in the brains of elderly normal subjects as well as $\mathrm{AD}$ sufferers does not preclude a role of the virus in the disease: there are many cases where an infectious agent infects far more people than are affected by disease; for example, the TB bacterium, Mycoplasma tuberculosis, causes the disease in only approximately $10 \%$ of those infected. It is likely that genetic factors determine whether or not an infected individual suffers from disease and indeed, in the case of HSV1 and AD, studies suggest that the combination of HSV1 in brain and carriage of a type 4 allele of the apolipoprotein $\mathrm{E}$ gene $(A P O E-\varepsilon 4)$ confers a strong risk of $\mathrm{AD}$, accounting for approximately $60 \%$ of $\mathrm{AD}$ patients [1]. In fact, $A P O E$ affects the outcome of infection in the case of several diverse microbes and, significantly, $A P O E-\varepsilon 4$ is a risk factor for cold sores [2], and studies on infected $A P O E$ transgenic animals by several groups support the concept that HSV1 in brain and $A P O E-\varepsilon 4$ carriage is particularly harmful [3-5].

"...the virus is usually dormant but can

be reactivated ... repeated reactivation causes cumulative damage and, eventually, Alzheimer's disease."

Further evidence for a role for HSV1 in AD comes from data linking HSV1 directly to the main neuropathological features of the disease, amyloid plaques and neurofibrillary tangles (NFT), which comprise mainly $\beta$-amyloid $(A \beta)$ and abnormally phosphorylated tau (P-tau), respectively. $\mathrm{A} \beta$ and $\mathrm{P}$-tau are implicated in disease progression but the causes of their formation are unknown. Tau is a microtubule-associated protein with a role in axonal transport, which is disrupted when tau is abnormally phosphorylated. The function of $A \beta$ is unclear but it exerts toxic effects on cells, especially in oligomeric form. Possibly it protects against pathogens, including bacteria [6] and HSV1 [7], as part of the innate immune response, but if eventually overproduced, it then becomes damaging [1]. Direct research linking HSV1 to these neuropathological features includes studies demonstrating that HSV1 infection of human neural cells in

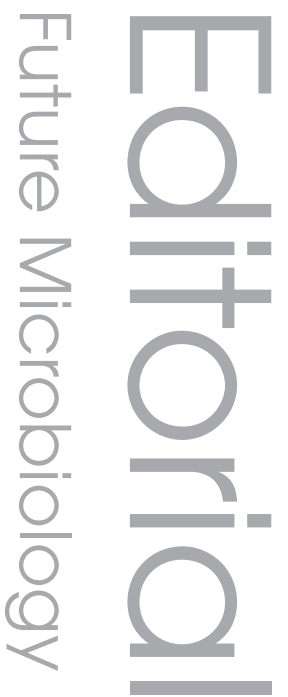

\section{Keywords}

- abnormally phosphorylated tau $=$ acyclovir $=$ Alzheimer's disease = antiviral agents - apolipoprotein E = $\beta$-amyloid - clinical trial $=$ herpes simplex virus type 1 = valacyclovir

\section{Future Medicine part of}


culture causes a striking increase in intracellular level of $A \beta\left[{ }^{8-10]}\right.$ and P-tau [11-13]. Furthermore, $\mathrm{A} \beta$ deposits are formed in the brains of HSV1infected mice [8] and HSV1 triggers AD-like caspase-3 activation and tau cleavage [13]. Moreover, the enzymes responsible for $A \beta$ and $P$-tau formation are increased in infected cells $[8,11,14]$ and dynamic interactions occur between amyloid precursor protein (APP), the precursor of $A \beta$, and HSV1, in ways that facilitate viral transport and interfere with normal APP transport and distribution [15]. Lastly, and very significantly, HSV1 DNA is located specifically within amyloid plaques of frontal and temporal cortices of AD patients [16]. This discovery, together with the HSV1-induced $A \beta$ deposition, suggests that HSV1 is involved in plaque and toxic oligomer formation, and hence it supports a causal role for HSV1 in AD. These data have led us to propose that the virus is usually dormant but can be reactivated - as it is in the peripheral nervous system - by events such as stress and general infections, and that repeated reactivation causes cumulative damage and, eventually, $\mathrm{AD}$, perhaps through $\mathrm{A} \beta$ and $\mathrm{P}$-tau production in $A P O E-\varepsilon 4$ carriers.

These data implicating HSV1 in AD suggest that antiviral treatment of the disease might slow or stop its progression in those patients who are seropositive for HSV1 (and therefore likely to harbor the virus in brain [unfortunately, detection of the virus in brain is currently possible only post-mortem]) and who are $A P O E-\varepsilon 4$ carriers. The main antiviral agent used for treating HSV1 infections is acyclovir (ACV), which specifically targets infected cells and viral DNA replication. We reasoned that ACV might be effective in treating AD only if it were to reduce the HSV1-induced production of $A \beta$ and P-tau, and as it acts on viral DNA replication, $A \beta$ and P-tau reduction would occur only if their production were dependent on viral DNA replication. We found that ACV substantially reduces the amount of $A \beta$ and P-tau in HSV1-infected cells in culture, as well as the amount of HSV1, which is as expected [17]. P-tau production depends on HSV1 replication and decreases to zero. $A \beta$ production depends at least partly on an earlier stage in the cycle, but is reduced greatly - presumably through the reduction in viral spread caused by the decreased viral DNA replication. Thus, these data suggest that ACV would be effective in treating AD.

A major advantage of using ACV is that, because it acts specifically on infected cells, it would not affect uninfected cells or the normal metabolism of infected cells which is in contrast to the harmful side-effects of many other treatments. In fact, the safety of ACV's biodrug, valacyclovir (VCV), which would be greatly preferable because of its five to tenfold greater oral bioavailability, is already proven, although it has not yet been tested in AD patients. VCV doses of $3 \mathrm{~g}$ per day have been used over a 2-year period in a trial for its use in multiple sclerosis, without causing any obvious adverse effect. The only contraindication currently known would be for patients with renal problems: if renal clearance of the drug is impaired, there is a risk of subsequent drug-derived neurotoxicity (which is reversible) and of crystaluria with renal shutdown (which may not be reversible). Hence, creatinine clearance would need to be closely monitored.

Further advantages would include the likelihood that VCV would prevent most viral damage, not just the production of $A \beta$ and P-tau, and so if other harmful products of HSV1 are involved in $\mathrm{AD}$ development, they too would be targeted. Additionally, VCV is relatively inexpensive. As to whether VCV gets to the brain, this appears not to be problematic, since in people with normal blood-cerebrospinal fluid (CSF) barrier function, including those who have recovered from HSE, ACV (derived from $\mathrm{VCV}$ ) is present in CSF at the inhibitory level for HSV1.

66

"...the evidence for a role of HSV1 in

Alzheimer's disease is strong and

convincing enough for a proof-of-concept clinical trial to be undertaken."

What are the possible problems in using VCV to treat AD? First, HSV1 might cause damage even when latent, and the latent virus would not be affected by VCV. However, it is much more likely that viral damage occurs when the latent virus reactivates from latency and during the subsequent viral replication and spread stages that are preventable by VCV. Indeed, the increases in $A \beta$ and P-tau, which are thought to be central to $\mathrm{AD}$ pathogenesis, are produced during acute HSV1 infection.

Second, monitoring of HSV1 in brain and the putative effects of an antiviral on its level and activity are not possible at present. In principle, these could be detected and assessed by investigating the presence of HSV1 DNA in CSF, as is performed in HSE patients, but the viral DNA persists in CSF for only approximately 1 week after acute infection [18], so that repeated CSF sampling would be required, which is obviously not feasible. However, in future, methods 
of imaging HSV1 in brain might be developed to the appropriate level of sensitivity.

The third issue relates to the possibility that the brain damage in $\mathrm{AD}$ is due at least partly to inflammation: HSV1 causes inflammation during acute infection, and perhaps during latency too $[19,20]$. However, this could be controlled by concurrent treatment with an anti-inflammatory agent.

An additional problem is that there is evidence that deposition of $A \beta$ occurs many years before overt disease. Possibly, the deposition causes little or no harm until it reaches a certain level, or else there are compensatory mechanisms, but these are eventually overwhelmed. The tipping point - the stage at which effective damage and overt disease start - and its nature is unknown, but treatment with VCV as early as possible should slow or stop further overt disease progression.
In conclusion, we consider that the evidence for a role of HSV1 in AD is strong and convincing enough for a proof-of-concept clinical trial to be undertaken. Further basic research carried out concurrently might at least partially solve the possible problems outlined above and, in particular, research on antivirals that act by different mechanisms would be invaluable for selecting the most suitable therapeutic agents.

\section{Financial \& competing interests disclosure}

The authors have no relevant affiliations or financial involvement with any organization or entity with a financial interest in or financial conflict with the subject matter or materials discussed in the manuscript. This includes employment, consultancies, honoraria, stock ownership or options, expert testimony, grants or patents received or pending, or royalties.

No writing assistance was utilized in the production of this manuscript.

\section{References}

1. Wozniak MA, Itzhaki RF. Antiviral agents in Alzheimer's disease: hope for the future? Ther. Adv. Neurol. Disord. 3, 141-152 (2010).

2. Itzhaki RF, Wozniak MA. Apolipoprotein E: microbial friend or foe? In: Apoproteins: Research Trends. Nova Science Publications, NY, USA (2009).

3. Burgos J S, Ramirez C, Sastre I, Valdivieso F. Effect of apolipoprotein $\mathrm{E}$ on the cerebral load of latent herpes simplex virus type 1 DNA. J. Virol. 80(11), 5383-5387 (2006).

4. Bhattacharjee PS, Neumann DM, Foster TP et al. Effect of human apolipoprotein $\mathrm{E}$ genotype on the pathogenesis of experimental ocular HSV-1. Exp. Eye Res. 87(2), 122-130 (2008).

5. Miller RM, Federoff HJ. Isoform-specific effects of ApoE on HSV immediate early gene expression and establishment of latency. Neurobiol. Aging 29(1), 71-77 (2008).

6. Soscia SJ, Kirby JE, Washicosky KJ et al. The Alzheimer's disease-associated amyloid beta-protein is an antimicrobial peptide. PLoS One 5(3), E9505 (2010).

7. Lukiw WJ, Cui JG, Yuan LY et al. Acyclovir or Abeta42 peptides attenuate HSV-1-induced miRNA-146a levels in human primary brain cells. Neuroreport 21(14), 922-927 (2010).

8. Wozniak MA, Itzhaki R F, Shipley SJ, Dobson CB. Herpes simplex virus infection causes cellular beta-amyloid accumulation and secretase upregulation. Neurosci. Lett. 429(2-3), 95-100 (2007).

9. Santana $S$, Recuero M, Bullido MJ, Valdivieso F, Aldudo J. Herpes simplex virus type I induces the accumulation of intracellular beta-amyloid in autophagic compartments and the inhibition of the non-amyloidogenic pathway in human neuroblastoma cells. Neurobiol. Aging 33(2), 430 E19-E33 (2011).

10. Piacentini R, Civitelli L, Ripoli C et al. HSV-1 promotes $\mathrm{Ca}\left({ }^{2+}\right)$-mediated APP phosphorylation and Abeta accumulation in rat cortical neurons. Neurobiol. Aging 32(12), 2323 E13-E26 (2010).

11. Wozniak MA, Frost AL, Itzhaki RF. Alzheimer's disease-specific tau phosphorylation is induced by herpes simplex virus type 1. J. Alzheimers Dis. 16, 341-350 (2009).

12. Zambrano A, Solis L, Salvadores N, Cortes M, Lerchundi R, Otth C. Neuronal cytoskeletal dynamic modification and neurodegeneration induced by infection with herpes simplex virus type 1. J. Alzheimers Dis. 14(3), 259-269 (2008).

13. Lerchundi R, Neira R, Valdivia $S$ et al. Tau Cleavage at D 421 by caspase- 3 is induced in neurons and astrocytes infected with herpes simplex virus type 1. J. Alzheimers Dis. 23, 513-520 (2011).
14. Ill-Raga G, Palomer E, Wozniak MA et al. Activation of PKR causes amyloid ss-peptide accumulation via de-repression of $B A C E 1$ expression. PLoS One 6(6), E21456 (2011).

15. Cheng S B, Ferland P, Webster P, Bearer EL. Herpes simplex virus dances with amyloid precursor protein while exiting the cell. PLoS One 6(3), E17966 (2011).

16. Wozniak MA, Mee AP, Itzhaki RF. Herpes simplex virus type 1 DNA is located within Alzheimer's disease amyloid plaques. J. Pathol. 217(1), 131-138 (2009).

17. Wozniak MA, Frost AL, Preston CM, Itzhaki RF. Antivirals reduce the formation of key Alzheimer's disease molecules in cell cultures acutely infected with herpes simplex virus type 1. PLoS One 6(10), E25152 (2011).

18. Mitchell PS, Espy MJ, Smith TF et al. Laboratory diagnosis of central nervous system infections with herpes simplex virus by PCR performed with cerebrospinal fluid specimens. J. Clin. Microbiol. 35(11), 2873-2877 (1997).

19. Carr DJ, Tomanek L. Herpes simplex virus and the chemokines that mediate the inflammation. Curr. Top. Microbiol. Immunol. 303, 47-65 (2006).

20. Marques CP, Cheeran MC, Palmquist JM, $\mathrm{Hu}$ S, Urban SL, Lokensgard JR. Prolonged microglial cell activation and lymphocyte infiltration following experimental herpes encephalitis. J. Immunol. 181(9), 6417-6426 (2008). 